\title{
Percutaneous "K-wireless" pedicle screw fixation technique: an evaluation of the initial experience of 100 screws with assessment of accuracy, radiation exposure, and procedure time
}

\author{
Steven M. Spitz, MD, Faheem A. Sandhu, MD, PhD, and Jean-Marc Voyadzis, MD \\ Department of Neurosurgery, MedStar Georgetown University Hospital, Washington, DC
}

OBJECT Percutaneous pedicle screws are used to provide rigid internal fixation in minimally invasive spinal procedures and generally require the use of Kirchner wires (or K-wires) as a guide for screw insertion. K-wires can bend, break, advance, or pull out during the steps of pedicle preparation and screw insertion. This can lead to increased fluoroscopic and surgical times and potentially cause neurological, vascular, or visceral injury. The authors present their experience with a novel "K-wireless" percutaneous pedicle screw system that eliminates the inherent risks of K-wire use.

METHODS A total of 100 screws were placed in 28 patients using the K-wireless percutaneous screw system. Postoperative dedicated spinal CT scans were performed in 25 patients to assess the accuracy of screw placement. Screw placement was graded $A$ through $D$ by 2 independent radiologists: $A=$ within pedicle, $B=$ breach $<2 \mathrm{~mm}, C=$ breach of 2-4 mm, and $D=$ breach $>4 \mathrm{~mm}$. Screw insertion and fluoroscopy times were also recorded in each case. Clinical complications associated with screw insertion were documented.

RESULTS A total of $100 \mathrm{~K}$-wireless percutaneous pedicle screws were placed into the lumbosacral spine in 28 patients. Postoperative CT was performed in 25 patients, thus the placement of only 90 screws was assessed. Eighty-seven screws were placed within the pedicle confines (Grade A), and 3 violated the pedicle (2 Grade B [1 lateral, 1 medial] and 1 Grade D [medial]) for an overall accuracy rate of $96.7 \%$. One patient required reoperation for screw repositioning due to a postoperative $L-5$ radiculopathy secondary to a Grade $D$ medial breach at $L-5$. This patient experienced improvement of the radiculopathy after reoperation. Average screw insertion and fluoroscopy times were 6.92 minutes and 22.7 seconds per screw, respectively.

CONCLUSIONS The results of this study demonstrate that the placement of K-wireless percutaneous pedicle screws is technically feasible and can be performed accurately and safely with short procedure and fluoroscopy times.

http://thejns.org/doi/abs/10.3171/2014.11.SPINE14181

KEY WORDS percutaneous pedicle screw; K-wireless; K-wire; minimally invasive; technique

$\mathrm{P}$ ERCUTANEOUs pedicle screw placement was originally described by Magerl in 1977 as a means to secure an external spinal fixation system for the treatment of spinal instability secondary to acute trauma or osteomyelitis. ${ }^{26}$ Since that time, the indications for percutaneous pedicle screw placement have greatly expanded due to advances in spinal instrumentation and surgical techniques. Today, percutaneous pedicle screws are routinely placed to supplement interbody fusion techniques for degenera- tive disc disease, spondylolisthesis, or scoliosis, and to stabilize thoracolumbar fractures. ${ }^{9}, 17,18,33,41$

The placement of pedicle screws percutaneously minimizes muscle dissection, decreases blood loss, and reduces infection rates, which has translated into improved hospital stays and better patient outcomes. ${ }^{6,12,20,34,39,43}$ However, the technique of screw insertion is technically demanding and requires a learning curve principally due to the use of Kirchner wires (or K-wires) and reliance on fluoroscopy

ABBREVIATIONS ALIF = anterior lumbar interbody fusion; $A P=$ anteroposterior; $L L I F=$ lateral lumbar interbody fusion; TLIF = transforaminal lumbar interbody fusion . SUBMITTED February 18, 2014. ACCEPTED November 24, 2014.

INCLUDE WHEN CITING Published online February 6, 2015; DOI: 10.3171/2014.11.SPINE14181.

DISCLOSURE Dr. Voyadzis and Dr. Sandhu are consultants for Spineart. The authors received no assistance (financial or otherwise) for the design and implementation of this study. 
due to the lack of tactile and visual feedback afforded by conventional open surgical techniques. The use of K-wires is not without risk. K-wires can bend, leading to difficulty with the passage of cannulated instruments over them. They can advance through the vertebral body, particularly in osteoporotic patients, causing vascular or visceral injury. ${ }^{16,28}$ They can pull out, injure neurological structures, produce a CSF leak, or break. Each of these potential complications can increase patient morbidity, operative time, radiation exposure, and surgeon frustration.

The elimination of K-wires in the application of percutaneous pedicle screws should reduce operative time and radiation exposure while avoiding the aforementioned risks. The following is a description and evaluation of the technique of "K-wireless" percutaneous pedicle screw insertion and our early experience with this system, assessing the accuracy of screw placement by postoperative CT, and evaluating operative and fluoroscopy time.

\section{Methods}

Twenty-eight consecutive patients undergoing lumbosacral fusion procedures with K-wireless percutaneous pedicle screws (Romeo, Spineart) were prospectively studied. All patients underwent instrumented spinal fusion for the treatment of degenerative disc disease, scoliosis, or spondylolisthesis after an unsuccessful trial of conservative management. Percutaneous pedicle screw fixation was used to augment single or multilevel minimally invasive transforaminal interbody fusion (TLIF), minimally invasive lateral lumbar interbody fusion (LLIF), or anterior lumbar interbody fusion (ALIF). If an ALIF or LLIF was performed, the patients were repositioned prone for posterior instrumentation. If a minimally invasive TLIF was performed, typically 2 percutaneous screws were placed on 1 side and 2 screws placed within the tubular retractor on the other side after decompression of the neural elements and interbody graft placement. Screws placed through the tubular retractor were completed using direct visualization of standard anatomical landmarks and thus were not studied. Screw insertion was completed using simultaneous anteroposterior (AP) and lateral fluoroscopic images with 2 fluoroscopy machines. In each case, operative time measured from the time of incision to final satisfactory screw placement was recorded by the operating room staff. These measurements excluded the placement of the rod and compression, distraction, or reduction maneuvers, as well as final tightening. All cases were performed by 2 senior spine surgeons (F.A.S. and J.M.V) with extensive experience in minimally invasive spinal techniques at MedStar Georgetown University Hospital in Washington, DC, and Calvert Memorial Hospital in Prince Frederick, MD.

\section{Fluoroscopy Time and Radiation Exposure}

Fluoroscopy time was recorded in each case from initial incision to final satisfactory placement of all pedicle screws. Average radiation dose output for each fluoroscopic unit used was collected from standard radiation dose output spreadsheets maintained for quality assurance purposes. In making this spreadsheet, the physicist used a 1.5- inch aluminum filter with an exposure meter placed $30 \mathrm{~cm}$ in front of the source generator (source-to-skin distance). This method, in effect, leads to a worst-case scenario when calculating radiation dose output, because the aluminum filter increases the penetration of the x-ray beam by removing low-energy photons. Radiation exposure (mR) was calculated by multiplying fluoroscopy time by the average radiation dose output per $\mathrm{C}$-arm (obtained from the quality assurance spreadsheets). Radiation dosimeters were not used to measure actual radiation exposure in any of the cases performed. Therefore, radiation exposure to the surgeon and operating room staff who were wearing protective lead aprons is not accurately reflected in this study. However, the above calculation more accurately reflects the radiation exposure incurred by the patient in a worst-case scenario.

\section{Operative Technique}

After induction of general anesthesia and intravenous administration of an antibiotic, the patient is intubated and placed prone on a Jackson table. The arms should be abducted less than $90^{\circ}$ with the elbows flexed and placed on arm boards. The hips are placed in extension to maximize lumbar lordosis. All pressure points are padded to prevent peripheral nerve palsies and skin breakdown. A urinary catheter is placed when surgeries are expected to last more than 2 hours. Proper AP images are obtained, demonstrating parallel endplates at the index level and a centered spinous process equidistant to well-visualized pedicles. A 2 -cm-long longitudinal incision is planned for each screw $3 \mathrm{~cm}$ lateral to the lateral border of the pedicle. Alternatively, a single incision for multilevel screw placement can be made. This lateral starting point ensures proper docking of the needle onto the junction of the lateral superior facet and transverse process (lateral pedicle border on AP fluoroscopy) away from and avoiding injury to the facet joint while maintaining a triangulating screw trajectory.

The patient is then prepared and draped in the normal sterile fashion. The incision is made after infiltration with a local anesthetic and an underlying longitudinal fasciotomy is performed with monopolar electrocautery to allow for the easier passage of instruments, including dilators. A pedicle probe (Fig. 1A) is advanced through the musculature and then positioned onto the junction of the lateral facet joint and transverse process using AP and lateral fluoroscopy (Fig. 1B). The probe is angled medially and then tapped with a mallet into the pedicle and vertebral body using standard fluoroscopic landmarks. As the probe approaches the pedicle-vertebral body junction on a lateral fluoroscopic view, it should lie at the center of the pedicle on AP imaging to avoid a medial canal breach. After insertion (Fig. 1C and D) the probe's handle and inner stylet are removed. Next, sequentially larger dilators are placed over the probe (Fig. 1E) followed by a final outer dilator (Fig. 1F and G). The tip of the outer dilator is serrated and tapped into the soft tissues. With the outer dilator held firmly by hand, the inner dilators and probe are removed. At this stage, a separate ball probe can be used to measure depth and ensure proper bone margins. An appropriately sized screw is then inserted through the outer dilator into the probed pedicle tract without the use of a K-wire 

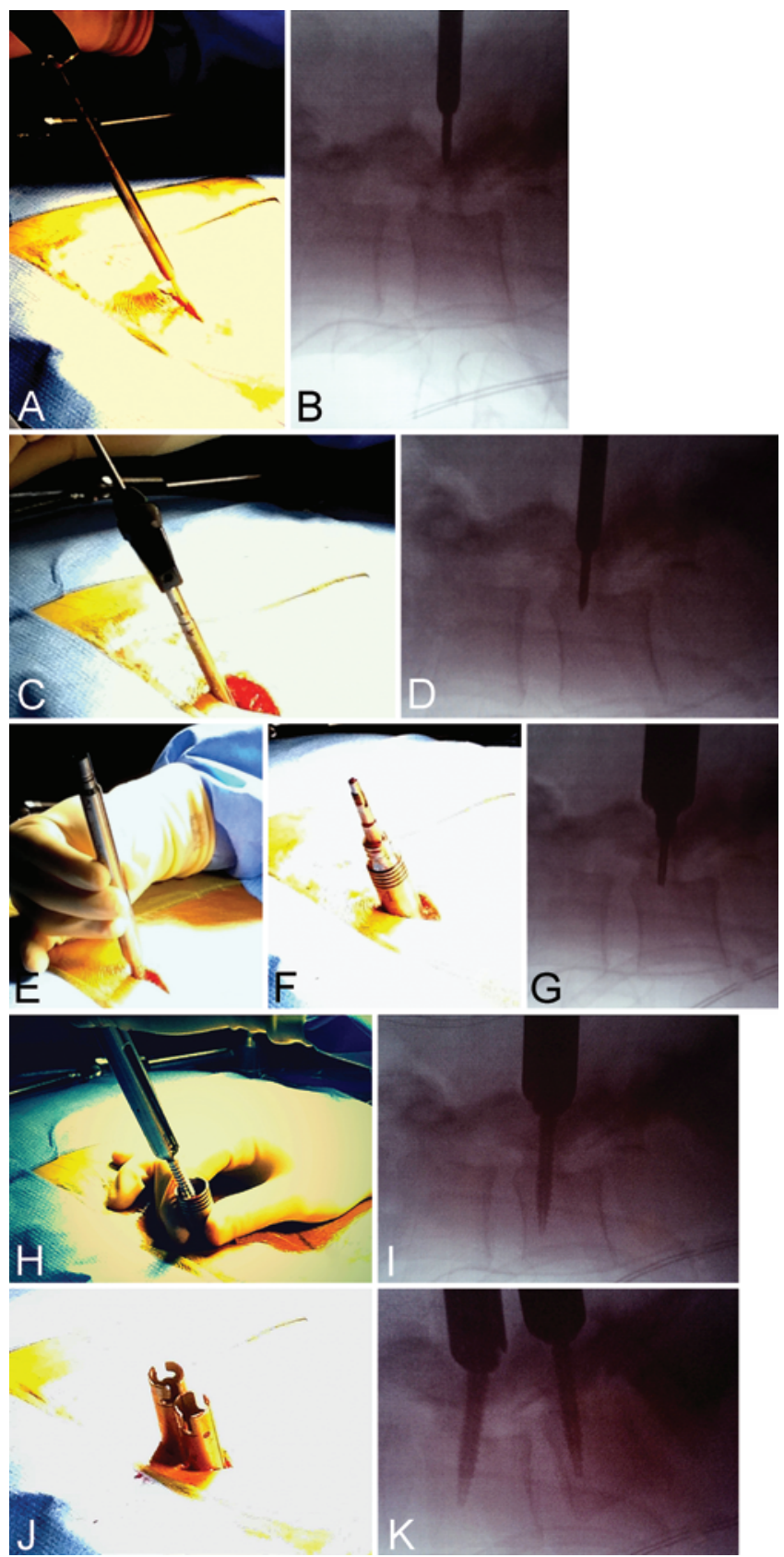

FIG. 1. Intraoperative and fluoroscopic images detailing the placement of K-wireless percutaneous pedicle screws with the patient prone. A: Introduction of the pedicle probe after incision of the skin and lumbodorsal fascia. B: Lateral fluoroscopic image showing initial docking of the pedicle probe at the lateral facet-transverse process junction overlying the pedicle of $\mathrm{L}-4$. C and D: Final pedicle probe placement after tapping with a mallet $(\mathrm{C})$ and lateral fluoroscopic confirmation of the probe's tip at the pedicle-vertebral body junction (D). E-H: Dilator placement over the probe after removal of the probe's handle $(E)$, followed by sequential dilation (F) and final dilator placement with fluoroscopic confirmation (G) after final dilator placement with the probe still in place. After removal of the probe and inner dilators, the final dilator is held firmly in place by hand $(\mathrm{H})$ as the pedicle screw and extender are inserted. I-K: Lateral fluoroscopic image demonstrating final screw and extender position after removal of the final dilator (I). This process is repeated for all subsequent screws ( $\mathrm{J}$ and $\mathrm{K}$ ). Figure is available in color online only.
(Fig. 1H). Lastly, appropriate pedicle screw placement is assessed with AP and lateral imaging (Fig. 1I) followed by removal of the outer dilator, leaving the screw and extender in place. The screws are self-centering and the tip is conical to allow for easier penetration into the pedicle. The exact same steps are repeated at other levels (Fig. 1J and $\mathrm{K}$ ) and a percutaneous rod is inserted and secured to the polyaxial screw heads with locking caps. The incisions are copiously irrigated and closed in layers.

\section{Postoperative CT Assessment}

Postoperative CT was obtained in 25 of 28 patients in the immediate postoperative period to assess pedicle screw placement. Therefore, a total of 10 of 100 pedicle screws were not included to assess placement accuracy. CT assessment of pedicle screw placement using axial, coronal, and sagittal reconstructions was independently reviewed by 2 senior neuroradiologists. All CT scans were adjusted to minimize metal artifact. A digital imaging system equipped with a measuring device accurate to 1 $\mathrm{mm}$ was then used for screw evaluation. The position of the screw relative to the pedicle was assessed and graded as follows: A, completely within the confines of the pedicle; $B$, pedicle wall breach less than $2 \mathrm{~mm}$; , pedicle wall breach between 2 and $4 \mathrm{~mm}$; and $\mathrm{D}$, pedicle wall breach greater than $4 \mathrm{~mm}$ (Table 1). The breach of the pedicle was qualified as medial, lateral, superior, or inferior. Any borderline position was automatically downgraded (i.e., from A to B, B to C, etc.) to give a worst-case scenario. In addition, any perforations of the anterior vertebral cortex were measured in millimeters along the axis of the screw.

\section{Illustrative Cases \\ Case 1}

A 60 -year-old woman presented with severe progressive back and right-leg pain refractory to multiple conservative treatment measures, including physical therapy and epidural injections. Her physical examination was remarkable for slight dorsiflexion weakness on the right with associated hypesthesia in an L-5 distribution. Magnetic resonance imaging studies showed a Grade 1 L4-5 spondylolisthesis with severe lumbar stenosis (Fig. 2A and B). The patient underwent a minimally invasive TLIF and L-4 laminectomy without complications. Percutaneous Kwireless pedicle screws were inserted first at L-4 (Fig. 2C) and L-5 (Fig. 2D) on the left side. Total fluoroscopy time and screw insertion time for both screws was 34 seconds and 21 minutes, respectively, resulting in an average time of 17 seconds of fluoroscopy and 10.5 minutes for each screw insertion. A tubular retractor was then placed on the right side and an L-4 laminectomy and right-sided TLIF

\section{TABLE 1. Pedicle screw position grade}

\begin{tabular}{cl}
\hline Grade & Screw Position Relative to Pedicle \\
\hline A & Completely w/in pedicle \\
\hline B & Breach $<2 \mathrm{~mm}$ \\
\hline C & Breach btwn $2 \& 4 \mathrm{~mm}$ \\
\hline D & Breach $>4 \mathrm{~mm}$ \\
\hline
\end{tabular}



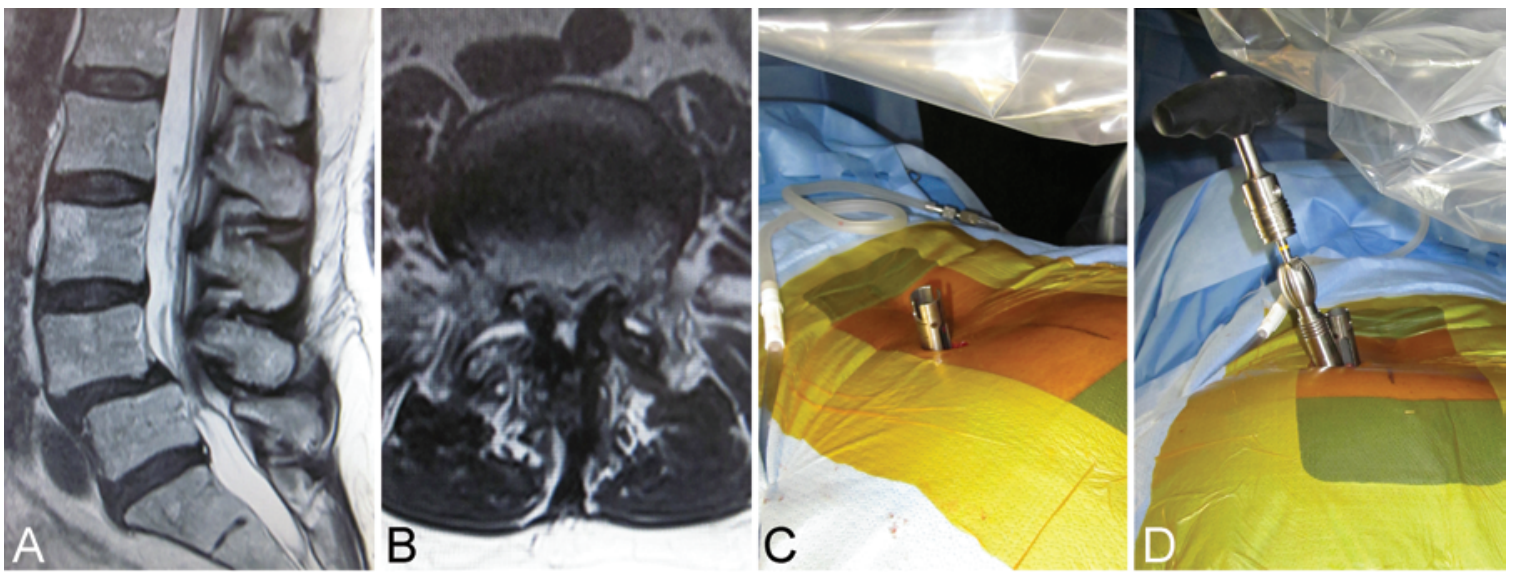
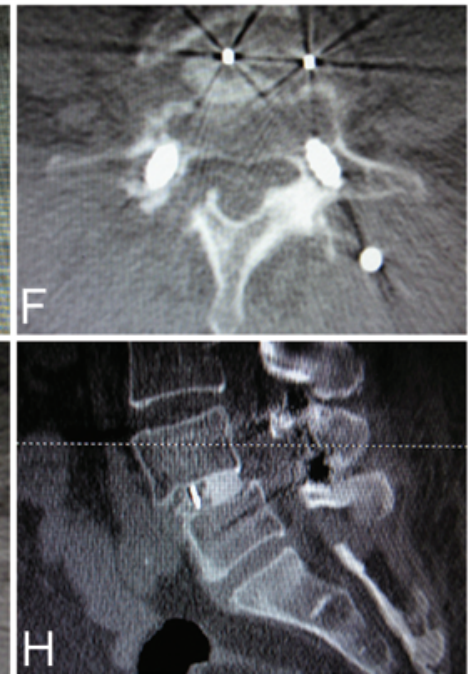

FIG. 2. Case 1. Minimally invasive TLIF and minimally invasive decompression augmented with K-wireless percutaneous pedicle screws. A and B: Preoperative sagittal T2-weighted MR image $(A)$ of the lumbar spine demonstrates a Grade 1 spondylolisthesis at L4-5 with severe bilateral lateral recess and central canal stenosis, as noted on axial T2-weighted MRI (B). C and D: Intraoperative photographs showing K-wireless screw placement on the contralateral (left) side prior to minimally invasive TLIF and decompression approached from the right. E-G: Postoperative axial CT scans demonstrating bilateral decompression (E) via a unilateral minimally invasive approach on the right side followed by minimally invasive TLIF. Grade A placement is shown for the left L-4 screw $(F)$ and Grade B placement for the left L-5 screw (G). H: Reformatted sagittal CT scan shows disc height restoration and spondylolisthesis reduction. Note that screws on the ipsilateral side of the minimally invasive TLIF approach were placed through the tubular retractor under direct vision and were not counted in this study. Figure is available in color online only. was completed with reduction and pedicle screw insertion through the retractor. ${ }^{33} \mathrm{~A}$ bilateral decompression of her severe canal stenosis was achieved from a unilateral approach through the tubular retractor by undercutting the inner aspect of the contralateral lamina and medial facet joint ${ }^{15,18,31,51}$ (Fig. 2E). It was believed that a contralateral decompression of the foraminal stenosis was not necessary given her unilateral symptoms. Her postoperative course was uneventful. She enjoyed complete resolution of her low-back and leg symptoms at 1 year. Follow-up CT showed Grade A placement at L-5 on the left (Fig. 2F) and Grade B placement ( $<2-\mathrm{mm}$ lateral breach) at L-4 on the left (Fig. 2G) with excellent reduction (Fig. 2H).

\section{Case 2}

A 45-year-old man presented with severe progressive low-back and left-leg pain refractory to multiple conservative treatments, including narcotic analgesics and both facet and epidural injections. His physical examination was notable only for hypesthesia in an L-5 distribution on the left. Lateral radiographic (Fig. 3A) and MRI studies demonstrated a Grade 1 isthmic spondylolisthesis at L5-S1 with associated bilateral foraminal stenosis (Fig. 3B and C). The patient underwent an L5-S1 ALIF with screw fixation into S-1 only. He was then positioned prone and percutaneous K-wireless pedicle screws were placed at L5-S1 bilaterally followed by reduction and rod securement. His postoperative course was uneventful with complete resolution of back and leg symptoms at 10 months with no narcotic consumption. Follow-up lateral radiography showed restoration of disc height and spondylolisthesis reduction (Fig. 3D). CT demonstrated accurate placement of all 4 screws with no evidence of pedicle breach (Grade A) and good restoration of neuroforaminal height via indirect decompression, thus obviating the need for a laminectomy in this case (Fig. 3E and F).

\section{Case 3}

A 50-year-old woman presented with severe progressive back and bilateral leg pain refractory to multiple conservative treatments including narcotic analgesics, physical therapy, and both epidural and facet injections. Her physical examination was notable for lumbosacral paraspinal muscle tenderness, and bilateral leg paresthesia. A lateral radiograph showed a Grade 1-2 spondylolisthesis at L4-5 with resultant bilateral foraminal stenosis (Fig. 4A). She underwent an L4-5 LLIF and was then repositioned prone for placement of percutaneous K-wireless pedicle screws at L-4 and L-5 bilaterally followed by reduction and rod securement. Her postoperative course was uneventful with improved back and bilateral leg symptoms at 1 year. Follow-up CT scans showed excellent reduction of her spon- 

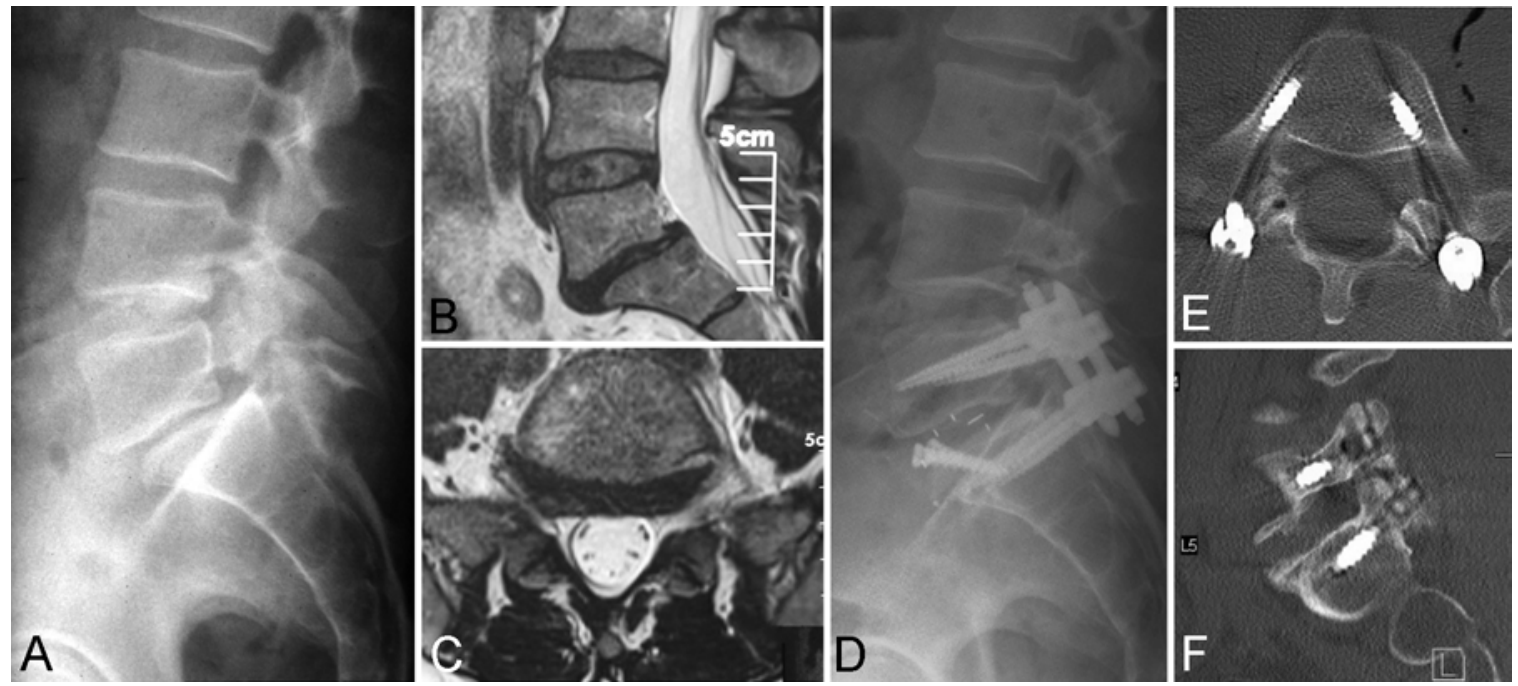

FIG. 3. Case 2. L5-S1 ALIF with subsequent K-wireless percutaneous pedicle screw instrumentation. A: Preoperative lateral radiograph showing a Grade 1 isthmic spondylolisthesis and disc space narrowing at L5-S1. B and C: Preoperative sagittal T2weighted MR image (B) again demonstrating a Grade 1 spondylolisthesis with bilateral foraminal stenosis on axial imaging (C). D: Postoperative lateral radiograph showing restoration of disc space height and spondylolisthesis reduction. E and F: Restoration of lateral recess area via indirect decompression as noted on postoperative axial (E) and left parasagittal (F) CT scans.

dylolisthesis with restoration of disc height (Fig. 4B) and Grade A screw placement at L-4 (Fig. 4C) and L-5 (Fig. 4D) bilaterally.

\section{Results}

A total of $100 \mathrm{~K}$-wireless percutaneous pedicle screws were placed in the lumbosacral spine in 28 patients with spondylolisthesis, degenerative disc disease, or scoliosis. The average patient age was 57.1 years (range 33-83 years) and 18 patients were women (Table 2). Screws were placed to augment minimally invasive TLIF $(n=20)$, minimally invasive $\operatorname{LLIF}(\mathrm{n}=8)$, and $\operatorname{ALIF}(\mathrm{n}=2)$. Blood loss in each case from screw insertion was negligible and not accurately measured but was believed to be less than 10 $\mathrm{ml}$ on average.

Immediate postoperative CT was completed in 25 of 28 patients. Only screws evaluated with postoperative CT were assessed for accurate placement, leaving a total of 90 screws assessed. Of the 90 screws evaluated, 2 were placed at L-2, 8 at L-3, 28 at L-4, 36 at L-5, and 16 at S-1 (Table 3). Eighty-seven screws were purely within the pedicle (Grade A) for an overall accuracy of $96.7 \%$. Three of the 90 screws penetrated the pedicle cortex. Two of these breaches were less than $2 \mathrm{~mm}$ (Grade B) and 1 was greater than $4 \mathrm{~mm}$ (Grade D), for an overall pedicle breach rate of 3.3\%. In further classifying the breached pedicle screws, 1 was lateral (Grade B) and 2 were medial (1 Grade B and 1 Grade D), with no superior or inferior breaches. Additionally, none of the screws breached the anterior vertebral cortex. The 1 patient with a Grade D medial breach at L-5 required reoperation due to a new postoperative foot weakness, thus resulting in a clinical complication rate related to aberrant screw placement of 3.6\%. This patient, who had osteoporosis, presented in a delayed fashion on postoperative Day 10 and the screw was found to enter medially into the hole created by the pedicle probe on direct visualization. This patient experienced improvement of radiculopathy, but had persistent weakness after reoperation.

The mean time of screw insertion calculated from initial skin incision to final satisfactory screw positioning based on fluoroscopic imaging was 6.92 minutes per screw (range 2.05-11.5 minutes; Table 4). Mean fluoroscopy time was 22.7 seconds per screw. Average total (AP and lateral) fluoroscopy time for insertion of all screws, ranging from 2 to 8 screws per case, was 1.26 minutes (range 0.5-2.65 minutes). The absorbed radiation dose averaged $543 \mathrm{mR}$ per case (range $119-1320 \mathrm{mR}$ ) and 162.9 $\mathrm{mR}$ (range 57.8-311 mR) per screw. All of these measurements excluded the placement of the rod, compression, distraction, or reduction maneuvers, and final tightening. Fluoroscopy time was not recorded in 1 patient and screw insertion time was not recorded in 2 patients; therefore, these patients were not included in the calculated average fluoroscopy and screw insertion times, respectively.

\section{Discussion}

The biomechanical strength afforded by pedicle screws is the impetus for their widespread use to rigidly fixate the unstable spine caused by various spinal disorders. Prior to the development of percutaneous pedicle fixation systems, pedicle screws were placed strictly via an open technique. This technique relies on a midline exposure with extensive lateral dissection and muscle retraction to visualize surgical landmarks and allow for a sufficient lateral to medial trajectory for screw placement. Alternatively, a paramedian approach can be used..$^{50}$ Open techniques without the use of intraoperative guidance systems have demonstrated pedicle breach rates of $6 \%$ to $39 \% .{ }^{4,11,13,14,22-24,35,40}$ Several more recent studies with the aid of computer navigation have shown pedicle breach rates of $0 \%$ to $19 \% .5,10,13,27,38$ This technique, although commonly used in modern spine surgery, is associated with a significant amount of intra- 


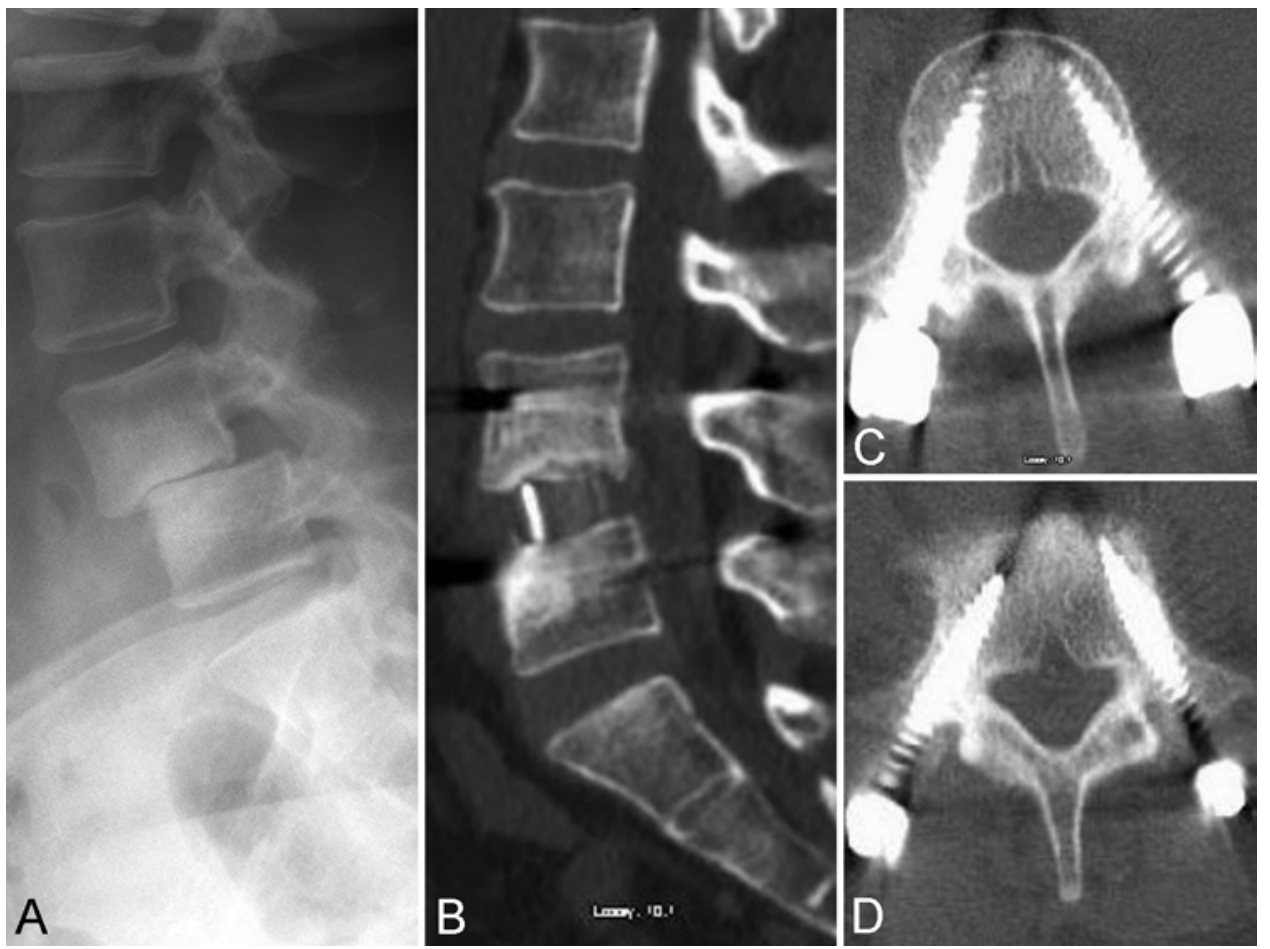

FIG. 4. Case 3. L4-5 LLIF followed by K-wireless percutaneous pedicle screw instrumentation. A: Lateral radiograph showing a Grade 1-2 spondylolisthesis and disc space narrowing at L4-5. B: Sagittal reformatted CT scan showing restoration of disc height and spondylolisthesis reduction. C and D: Axial CT scans demonstrate Grade A screw placement bilaterally at L-4 (C) and L-5 (D).

operative blood loss, muscle necrosis, and atrophy, which translates to an increase in postoperative pain and hospital length of stay. ${ }^{6,12,20,34,39,43}$

Percutaneous pedicle screw placement, first described by Magerl in 1977 for spinal external fixation, ${ }^{26}$ was first applied to the minimally invasive TLIF by Foley et al. ${ }^{9}$ Percutaneous screws are now commonly placed following various interbody fusion techniques and for the restoration of spinal stability associated with traumatic and neoplastic lesions. $5,7,9,17,32,33,36,41,45,46,48$ The placement of percutaneous pedicle screws has been shown to be both safe and efficacious, ${ }^{25,32,38,39,44,49}$ while offering distinct advantages over traditional open surgical techniques. These advantages include a smaller incision, less muscle dissection and thus less muscle necrosis and atrophy, and a decrease in blood loss, postoperative pain, and hospital length of stay. ${ }^{2,8,34,41}$ The technique of percutaneous screw placement does require time and patience. The surgeon must learn to operate with minimal tactile feedback, while relying on radiological images to visualize spinal anatomical landmarks. This generally translates during the learning curve to longer operative times and a heightened exposure to ionizing radiation for the surgeon, patient, and operating room staff. ${ }^{46}$

The accuracy of percutaneous pedicle screw placement, like the open technique, has been subject to several cadaveric and clinical studies due to the complex 3D anatomy and intimate relationship of the spine to important neurological, vascular, and visceral structures. In a study by Wiesner et al. that used postoperative thin-slice CT scans, 408 pedicle screws were placed percutaneously, with a breach rate of 6.6\%; most of the breaches were medial and more often affected the S-1 pedicles. ${ }^{49}$ A $10 \%$ breach rate was demonstrated in a cadaveric correlative study, also by Weisner and colleagues, after final dissection of the specimens. ${ }^{48}$ Schizas et al. reported an overall breach rate of $23 \%$ and a $3.3 \%$ severe frank penetration rate in 60 percutaneously placed pedicle screws. One patient required reoperation for an S-1 radiculopathy due to a frankly medially misplaced screw. ${ }^{42}$ Park et al. demonstrated an overall breach rate of $18 \%$ in 172 screws placed in the thoracic and lumbosacral spine in trauma patients. There was a significant breach rate $(>2 \mathrm{~mm})$ of $2.9 \%$. No patient required reoperation due to screw malposition. ${ }^{32}$ In a study of 287 screws placed in 67 patients, 1 screw $(<1 \%)$ was found to be misplaced. However, only 148 screws were graded using postoperative $\mathrm{CT}$, thus possibly underestimating the true breach rate. ${ }^{36}$ Smith et al. reported an overall pedicle breach rate of $6.2 \%$. Of the 601 pedicle screws placed using fluoroscopic guidance, 22 had a significant breach greater than $3 \mathrm{~mm}(3.7 \%)$ and 2 of their 151 patients had transient radiculopathies related to aberrant screw placement. ${ }^{44}$ The neurological injury from misplaced percutaneous pedicle screws ranges between $2 \%$ and $12.5 \%$ as determined by several patient series. ${ }^{19,25,42,44,47,49}$

In the present study using the K-wireless percutaneous screw system with biplanar fluoroscopy, 87 of 90 screws were placed within the confines of the pedicle for an overall breach rate of $3.3 \%$, which is consistent with other published reports. ${ }^{30,32,36,39,42,44,47,49}$ In further examining the 3 pedicle breaches, 2 were less than $2 \mathrm{~mm}$. It has been demonstrated that in the lumbar spine, there is a $2-\mathrm{mm}$ "safe zone" that represents the epidural space in which there is 
TABLE 2. Patient demographics

\begin{tabular}{ll}
\hline \multicolumn{1}{c}{ Variable } & \multicolumn{1}{c}{ Value } \\
\hline Patients & 28 \\
\hline Mean age in yrs (range) & $57.1(33-83)$ \\
\hline Men (\%) & $10(36)$ \\
\hline Women (\%) & $18(64)$ \\
\hline No. of screws at vertebral level (\%) & $0(0)$ \\
\hline L-1 & $2(2)$ \\
\hline L-2 & $8(9)$ \\
\hline L-3 & $28(31)$ \\
\hline L-4 & $36(40)$ \\
\hline L-5 & $16(18)$ \\
\hline S-1 & $90(100)$ \\
\hline Total & 5 \\
\hline Indication & 22 \\
\hline Degenerative disc disease & 1 \\
\hline Spondylolisthesis & \\
\hline Degenerative scoliosis & 20 \\
\hline Procedure & 8 \\
\hline TLIF & \\
\hline LLIF & \\
\hline ALIF & \\
\hline
\end{tabular}

little risk to the spinal cord or cauda equina. ${ }^{14}$ Therefore, a significant breach in our study was deemed to be greater than $2 \mathrm{~mm}$, which corresponds to a Grade C or D breach. With this in mind, there was only 1 screw out of 90 with a breach greater than $2 \mathrm{~mm}$, for a significant breach rate of $1.1 \%$. As the lumbar spine has a 2-mm "safe zone," neither of the 2 Grade B screws caused any neurological sequelae, while the 1 Grade D screw required revision surgery for screw removal due to a newly developed foot drop postoperatively. This patient had osteoporosis and the screw entry site was noted to be medial to the original hole created by the pedicle probe on visual inspection at revision. The tapered nature of the screws makes them easy to insert in osteoporotic bone, even without prior preparation of the pedicle. Thus, caution should be exercised when considering the K-wireless screw system in patients with osteoporosis. In the context of patient outcome, 1 of 28 patients developed a neurological deficit, for a clinical complication rate of $3.6 \%$ in relation to aberrant screw placement. To the authors' knowledge, there are currently no other reports of fluoroscopy-guided percutaneous pedicle screw placement techniques without the use of K-wires.

Fluoroscopy remains the most commonly used imaging modality to visualize spinal anatomical landmarks for screw insertion, although various other computer-assisted image guidance systems exist., ${ }^{1,21,30}$ The use of fluoroscopy exposes the patient, surgeon, and operating room staff to ionizing radiation. In fact, fluoroscopically assisted open thoracolumbar pedicle-screw placement exposes the spine surgeon to radiation dose rates up to 10-12 times greater than other, nonspinal musculoskeletal procedures. ${ }^{37}$ This amount of radiation is likely even larger when using biplanar fluoroscopy for percutaneous pedicle screw placement. In a cadaveric study using biplanar fluoroscopy for the placement of 10 lumbar percutaneous pedicle screws, Mroz et al. reported a total fluoroscopy time of 4 minutes $56 \mathrm{sec}-$ onds, with an average of 29 seconds per screw. ${ }^{29}$ Bindal et al. reported a mean fluoroscopy time of 1.69 minutes for screw placement per case in 24 patients undergoing 1- and 2-level minimally invasive TLIF. ${ }^{3}$ In our series, the average fluoroscopy time for insertion of all screws was 1.26 minutes per case and 22.7 seconds per screw, which is less than that noted in previously published studies.

Although fluoroscopy time is a practical means for estimating radiation exposure in regular clinical practice, variables such as average radiation output per fluoroscopy unit and surgeon positioning relative to the radiation source are not accurately accounted for. Radiation exposure to the surgeon during percutaneous pedicle screw placement has been reported in the literature. In a study by Mroz et al., radiation exposure was measured with strategically placed radiation dosimeters at the waist (under a lead apron) and the surgeon's dominant hand. The total radiation exposure to the waist (under a lead apron) was less than $10 \mathrm{mrem}$ (below reportable dose), and $103 \mathrm{mrem}$ to the dominant hand. The authors concluded that placing 6396 percutaneous screws would exceed the annual occupational dose limit to the extremities. However, the surgeon used the hands-off technique and stood opposite to the $\mathrm{x}$-ray beam source, which may significantly lower the radiation exposure..$^{29}$ Bindal et al. ${ }^{3}$ similarly used variously placed radiation dosimeters to assess radiation exposure. This study reported a mean radiation exposure per case of 76 mrem to the surgeon's dominant hand and 27 mrem to the waist (protected with a lead apron). The authors concluded that the annual occupational exposure limits to the torso could be exceeded if a surgeon performed more than

TABLE 3. Pedicle screw breach rate (total and per vertebral level)

\begin{tabular}{cccccc}
\hline Vertebral Level & $\begin{array}{c}\text { Screws per Vertebral } \\
\text { Level }\end{array}$ & No. of Breaches & Direction of Breach (n) & Grade of Breach (n) & Breach Rate (\%) \\
\hline L-1 & 0 & 0 & & & 0 \\
\hline L-2 & 2 & 0 & & & 0 \\
\hline L-3 & 8 & 0 & & B (2) & 7.1 \\
\hline L-4 & 28 & 2 & Medial (1), Lateral (1) & D (1) \\
\hline L-5 & 36 & 1 & Medial (1) & 0 \\
\hline S-1 & 16 & 0 & & & 3.3 \\
\hline Total & 90 & 3 & & & 0 \\
\hline
\end{tabular}


TABLE 4. Fluoroscopy times, radiation exposure, and screw insertion times in all patients

\begin{tabular}{|c|c|c|c|c|}
\hline Case No. & $\begin{array}{l}\text { No. of Levels } \\
\text { Treated }\end{array}$ & $\begin{array}{l}\text { Insertion Time per Screw } \\
\text { (min) }\end{array}$ & $\begin{array}{c}\text { Total Fluoroscopy Time per } \\
\text { Case (sec) }\end{array}$ & $\begin{array}{l}\text { Total Radiation Exposure to Patient } \\
\qquad(\mathrm{mR})\end{array}$ \\
\hline 1 & 1 & NA & NA & NA \\
\hline 2 & 1 & 11.25 & 150 & 1245 \\
\hline 3 & 1 & 10.0 & 97 & 805 \\
\hline 4 & 1 & 10.5 & 34 & 119 \\
\hline 5 & 1 & 11.5 & 59 & 489 \\
\hline 6 & 3 & 9.13 & 148 & 1228 \\
\hline 7 & 1 & 10.25 & 159 & 1320 \\
\hline 8 & 1 & 7.00 & 36 & 299 \\
\hline 9 & 1 & 8.50 & 65 & 227.5 \\
\hline 10 & 1 & 7.94 & 42 & 348.6 \\
\hline 11 & 2 & 9.75 & 66 & 231 \\
\hline 12 & 1 & 5.30 & 30 & 249 \\
\hline 13 & 2 & 6.69 & 80 & 664 \\
\hline 14 & 1 & 6.54 & 43 & 150.5 \\
\hline 15 & 1 & 9.59 & 60 & 210 \\
\hline 16 & 2 & 6.28 & 72 & 597.6 \\
\hline 17 & 2 & NA & 81 & 672.3 \\
\hline 18 & 1 & 5.00 & 33 & 273.9 \\
\hline 19 & 1 & 5.50 & 35 & 122.5 \\
\hline 20 & 1 & 4.91 & 126 & 1046 \\
\hline 21 & 1 & 2.75 & 58 & 481.4 \\
\hline 22 & 1 & 5.17 & 60 & 498 \\
\hline 23 & 1 & 2.05 & 140 & 490 \\
\hline 24 & 2 & 3.06 & 117 & 971.1 \\
\hline 25 & 1 & 3.06 & 62 & 514.6 \\
\hline 26 & 1 & 2.65 & 51 & 423.3 \\
\hline 27 & 1 & 9.46 & 102 & 846.6 \\
\hline 28 & 1 & 5.98 & 40 & 140 \\
\hline Average & 1.25 & 6.92 & 75.8 & 543 \\
\hline Range & $1-3$ & $2.05-11.5$ & $30-159$ & $119-1320$ \\
\hline
\end{tabular}

$\mathrm{NA}=$ not available.

194 of these procedures annually. Additionally, the calculated average maximum patient skin exposure was 138.3 mGy $(59.5 \mathrm{mGy}$ posteroanterior view and $78.8 \mathrm{mGy}$ lateral view), which equates to $13,830 \mathrm{mR}$. This study may have underestimated the total amount of radiation exposure as fluoroscopy was only used for screw placement and not for placement of the intervertebral graft, or rod.

The present study did not assess radiation exposure to the surgeon because radiation dosimeters were not used to specifically assess pedicle screw placement. By multiplying the average radiation dose output per $\mathrm{C}$-arm with fluoroscopy time, an estimate of radiation exposure to the patient can be obtained. Using this calculation, average radiation exposure to the patient was $5.43 \mathrm{mGy}(543 \mathrm{mR})$ per case and $1.63 \mathrm{mGy}(163 \mathrm{mR})$ per screw. These results do not reflect radiation exposure to the surgeon or operating room staff, which is typically significantly less because of the use of lead aprons and surgeon positioning away from the radiation source. Secondly, in making the quality assurance spreadsheet, the physicist used a 1.5-inch aluminum filter placed in front of the source generator, which increases the penetration of the x-ray beam as previously described. Thus, the calculated radiation output is exaggerated in comparison with normal clinical use. This calculated radiation exposure of $543 \mathrm{mR}$ more accurately depicts a worst-case scenario for the patient who is not wearing a protective lead apron. A valid comparison can be made between our calculated radiation exposure and the average maximum patient skin exposure calculated in the above study by Bindal et al. The calculated average maximum patient skin exposure, which was calculated in a similar manner to our study, was $138.3 \mathrm{mGy}$ per case and $29.1 \mathrm{mGy}$ per screw. ${ }^{3}$ This value is higher than the average radiation exposure calculated in our study.

The most common technique for placement of percutaneous pedicle screws utilizes K-wires to help guide cannulated taps and screws. Although K-wires serve as useful guides for cannulated screws, they have several limitations, including wire bending and breakage, and pullout leading to increased procedural time and potentially in- 
creased fluoroscopy use. In addition, K-wire migration may lead to neurological, vascular, or visceral injury, especially in patients with poor bone quality. This injury is rarely catastrophic; however, the small surface area and sharp tapered end of the K-wire decreases tactile feedback and may increase the probability of migration through the cortical boundaries of the vertebrae. Heini et al. reported a case of fatal cardiac tamponade caused by a prick injury of the right coronary artery due to K-wire migration during a T-11 burst fracture reduction and transpedicular stabilization procedure. The authors stated that K-wire migration potentially occurred while temporarily covering the field with sterile towels to verify correct position with AP fluoroscopy. ${ }^{16}$ In a retrospective review of 525 percutaneously placed pedicle screws, Mobbs and Raley reported 7 anterior vertebral body breaches of the K-wire. Of the reported breaches, 2 were associated with a retroperitoneal hematoma and ileus, but neither patient required a blood transfusion or surgical intervention. The authors concluded that catastrophic vascular and/or bowel injury, albeit rare, are potential complications that must be avoided by conscientious attention to meticulous technique while placing and inserting taps and screws over the K-wire. ${ }^{28}$ In our series using K-wireless percutaneous screws, the limitations of $\mathrm{K}$-wires were eliminated.

There are several potential limitations with this study. Our data were prospectively collected from 2 experienced spine surgeons who specialize in minimally invasive spinal techniques and were reviewed retrospectively. Therefore, the results portrayed in this series may not be representative of the surgeon with less experience utilizing these techniques. This effect may be partly mitigated due to the fact that neurosurgical residents were involved in the majority of the cases. In addition, this study lacks significant controls due to the fact that the 2 primary surgeons in this study rarely find it necessary to place pedicle screws via the open technique. Furthermore, this paper exclusively attempts to describe the technique of percutaneous pedicle screw placement without reliance on $\mathrm{K}$-wires. Comparison of this technique to conventional $\mathrm{K}$-wire techniques is of future interest. A further limitation may be the inherent inaccuracy of our calculation of radiation exposure as radiation dosage was derived from the average radiation output of the fluoroscopy machine multiplied by fluoroscopy time. This technique of converting fluoroscopy time to radiation exposure in $\mathrm{mR}$ is less accurate than measuring actual radiation doses with the use of strategically placed radiation dosimeters, as noted previously.

\section{Conclusions}

This prospective case series of percutaneous pedicle screw placement using a K-wireless system demonstrates that percutaneous pedicle screws can be placed safely without the use of $\mathrm{K}$-wires with a relatively low overall breach rate of $3.3 \%$ and a clinically significant breach rate of $1.1 \%$. Screw placement and fluoroscopy times were reduced when compared with other published series. Caution should be exercised when considering percutaneous screw placement in osteoporotic patients using this technique due to the conical screw design.

\section{References}

1. Abul-Kasim K, Söderberg M, Selariu E, Gunnarsson M, Kherad M, Ohlin A: Optimization of radiation exposure and image quality of the cone-beam O-arm intraoperative imaging system in spinal surgery. J Spinal Disord Tech 25:5258,2012

2. Bastian L, Knop C, Lange U, Blauth M: [Transpedicular implantation of screws in the thoracolumbar spine. Results of a survey of methods, frequency and complications.] Orthopade 28:693-702, 1999 (Ger)

3. Bindal RK, Glaze S, Ognoskie M, Tunner V, Malone R, Ghosh S: Surgeon and patient radiation exposure in minimally invasive transforaminal lumbar interbody fusion. $\mathbf{J}$ Neurosurg Spine 9:570-573, 2008

4. Castro WH, Halm H, Jerosch J, Malms J, Steinbeck J, Blasius S: Accuracy of pedicle screw placement in lumbar vertebrae. Spine (Phila Pa 1976) 21:1320-1324, 1996

5. Choi WW, Green BA, Levi AD: Computer-assisted fluoroscopic targeting system for pedicle screw insertion. Neurosurgery $47: 872-878,2000$

6. Datta G, Gnanalingham KK, Peterson D, Mendoza N, O'Neill K, Van Dellen J, et al: Back pain and disability after lumbar laminectomy: is there a relationship to muscle retraction? Neurosurgery 54:1413-1420, 2004

7. Deutsch H, Boco T, Lobel J: Minimally invasive transpedicular vertebrectomy for metastatic disease to the thoracic spine. J Spinal Disord Tech 21:101-105, 2008

8. Dhall SS, Wang MY, Mummaneni PV: Clinical and radiographic comparison of mini-open transforaminal lumbar interbody fusion with open transforaminal lumbar interbody fusion in 42 patients with long-term follow-up. J Neurosurg Spine 9:560-565, 2008

9. Foley KT, Holly LT, Schwender JD: Minimally invasive lumbar fusion. Spine (Phila Pa 1976) 28 (15 Suppl):S26-S35, 2003

10. Fu TS, Chen LH, Wong CB, Lai PL, Tsai TT, Niu CC, et al: Computer-assisted fluoroscopic navigation of pedicle screw insertion: an in vivo feasibility study. Acta Orthop Scand 75:730-735, 2004

11. Gaines RW Jr: The use of pedicle-screw internal fixation for the operative treatment of spinal disorders. J Bone Joint Surg Am 82-A:1458-1476, 2000

12. Gejo R, Matsui H, Kawaguchi $Y$, Ishihara H, Tsuji H: Serial changes in trunk muscle performance after posterior lumbar surgery. Spine (Phila Pa 1976) 24:1023-1028, 1999

13. Gelalis ID, Paschos NK, Pakos EE, Politis AN, Arnaoutoglou CM, Karageorgos AC, et al: Accuracy of pedicle screw placement: a systematic review of prospective in vivo studies comparing free hand, fluoroscopy guidance and navigation techniques. Eur Spine J 21:247-255, 2012

14. Gertzbein SD, Robbins SE: Accuracy of pedicular screw placement in vivo. Spine (Phila Pa 1976) 15:11-14, 1990

15. Guiot BH, Khoo LT, Fessler RG: A minimally invasive technique for decompression of the lumbar spine. Spine (Phila Pa 1976) 27:432-438, 2002

16. Heini P, Schöll E, Wyler D, Eggli S: Fatal cardiac tamponade associated with posterior spinal instrumentation. A case report. Spine (Phila Pa 1976) 23:2226-2230, 1998

17. Holly LT, Schwender JD, Rouben DP, Foley KT: Minimally invasive transforaminal lumbar interbody fusion: indications, technique, and complications. Neurosurg Focus 20(3):E6, 2006

18. Isaacs RE, Podichetty VK, Santiago P, Sandhu FA, Spears J, Kelly K, et al: Minimally invasive microendoscopy-assisted transforaminal lumbar interbody fusion with instrumentation. J Neurosurg Spine 3:98-105, 2005

19. Jeanneret B, Jovanovic M, Magerl F: Percutaneous diagnostic stabilization for low back pain. Correlation with results after fusion operations. Clin Orthop Relat Res (304):130-138, 1994 
20. Kawaguchi Y, Matsui H, Tsuji H: Back muscle injury after posterior lumbar spine surgery. A histologic and enzymatic analysis. Spine (Phila Pa 1976) 21:941-944, 1996

21. Kim CW, Lee YP, Taylor W, Oygar A, Kim WK: Use of navigation-assisted fluoroscopy to decrease radiation exposure during minimally invasive spine surgery. Spine J 8:584-590, 2008

22. Kosmopoulos V, Schizas C: Pedicle screw placement accuracy: a meta-analysis. Spine (Phila Pa 1976) 32:E111-E120, 2007

23. Laine T, Lund T, Ylikoski M, Lohikoski J, Schlenzka D: Accuracy of pedicle screw insertion with and without computer assistance: a randomised controlled clinical study in 100 consecutive patients. Eur Spine J 9:235-240, 2000

24. Laine T, Mäkitalo K, Schlenzka D, Tallroth K, Poussa M, Alho A: Accuracy of pedicle screw insertion: a prospective CT study in 30 low back patients. Eur Spine J 6:402-405, 1997

25. Lowery GL, Kulkarni SS: Posterior percutaneous spine instrumentation. Eur Spine J 9 (Suppl 1):S126-S130, 2000

26. Magerl FP: Stabilization of the lower thoracic and lumbar spine with external skeletal fixation. Clin Orthop Relat Res (189): $125-141,1984$

27. Merloz P, Troccaz J, Vouaillat H, Vasile C, Tonetti J, Eid A, et al: Fluoroscopy-based navigation system in spine surgery. Proc Inst Mech Eng H 221:813-820, 2007

28. Mobbs RJ: Raley DA: Complications with K-wire insertion for percutaneous pedicle screws. J Spinal Disord Tech 27:390-394, 2014

29. Mroz TE, Abdullah KG, Steinmetz MP, Klineberg EO, Lieberman IH: Radiation exposure to the surgeon during percutaneous pedicle screw placement. J Spinal Disord Tech 24:264-267, 2011

30. Nottmeier EW, Fenton D: Three-dimensional image-guided placement of percutaneous pedicle screws without the use of biplanar fluoroscopy or Kirschner wires: technical note. Int J Med Robot 6:483-488, 2010

31. Palmer S, Turner R, Palmer R: Bilateral decompressive surgery in lumbar spinal stenosis associated with spondylolisthesis: unilateral approach and use of a microscope and tubular retractor system. Neurosurg Focus 13(1):E4, 2002

32. Park DK, Thomas AO, St. Clair S, Bawa M: Percutaneous lumbar and thoracic pedicle screws: a trauma experience. J Spinal Disord Tech 27:154-161, 2014

33. Park P, Foley KT: Minimally invasive transforaminal lumbar interbody fusion with reduction of spondylolisthesis: technique and outcomes after a minimum of 2 years' follow-up. Neurosurg Focus 25(2):E16, 2008

34. Park Y, Ha JW: Comparison of one-level posterior lumbar interbody fusion performed with a minimally invasive approach or a traditional open approach. Spine (Phila Pa 1976) 32:537-543, 2007

35. Parker SL, McGirt MJ, Farber SH, Amin AG, Rick AM, Suk I, et al: Accuracy of free-hand pedicle screws in the thoracic and lumbar spine: analysis of 6816 consecutive screws. Neurosurgery 68:170-178, 2011

36. Powers CJ, Podichetty VK, Isaacs RE: Placement of percutaneous pedicle screws without imaging guidance. Neurosurg Focus 20(3):E3, 2006

37. Rampersaud YR, Foley KT, Shen AC, Williams S, Solomito $\mathrm{M}$ : Radiation exposure to the spine surgeon during fluoroscopically assisted pedicle screw insertion. Spine (Phila Pa 1976) 25:2637-2645, 2000

38. Ravi B, Zahrai A, Rampersaud R: Clinical accuracy of computer-assisted two-dimensional fluoroscopy for the percutaneous placement of lumbosacral pedicle screws. Spine (Phila Pa 1976) 36:84-91, 2011

39. Ringel F, Stoffel M, Stüer C, Meyer B: Minimally invasive transmuscular pedicle screw fixation of the thoracic and lumbar spine. Neurosurgery 59 (4 Suppl 2):ONS361-ONS367, 2006

40. Roy-Camille R, Saillant G, Mazel C: Internal fixation of the lumbar spine with pedicle screw plating. Clin Orthop Relat Res (203):7-17, 1986

41. Scheufler KM, Dohmen H, Vougioukas VI: Percutaneous transforaminal lumbar interbody fusion for the treatment of degenerative lumbar instability. Neurosurgery 60 (4 Suppl 2):203-213, 2007

42. Schizas C, Michel J, Kosmopoulos V, Theumann N: Computer tomography assessment of pedicle screw insertion in percutaneous posterior transpedicular stabilization. Eur Spine J 16:613-617, 2007

43. Schwender JD, Holly LT, Rouben DP, Foley KT: Minimally invasive transforaminal lumbar interbody fusion (TLIF): technical feasibility and initial results. J Spinal Disord Tech 18 Suppl:S1-S6, 2005

44. Smith ZA, Sugimoto K, Lawton CD, Fessler RG: Incidence of lumbar spine pedicle breach after percutaneous screw fixation: a radiographic evaluation of 601 screws in 151 patients. J Spinal Disord Tech 27:358-363, 2014

45. Tredway TL, Santiago P, Hrubes MR, Song JK, Christie SD, Fessler RG: Minimally invasive resection of intraduralextramedullary spinal neoplasms. Neurosurgery 58 (1 Suppl):ONS52-ONS58, 2006

46. Voyadzis JM: The learning curve in minimally invasive spine surgery. Semin Spine Surg 23:9-13, 2011

47. Wang MY, Pineiro G, Mummaneni PV: Stimulus-evoked electromyography testing of percutaneous pedicle screws for the detection of pedicle breaches: a clinical study of 409 screws in 93 patients. J Neurosurg Spine 13:600-605, 2010

48. Wiesner L, Kothe R, Rüther W: Anatomic evaluation of two different techniques for the percutaneous insertion of pedicle screws in the lumbar spine. Spine (Phila Pa 1976) 24:15991603,1999

49. Wiesner L, Kothe R, Schulitz KP, Rüther W: Clinical evaluation and computed tomography scan analysis of screw tracts after percutaneous insertion of pedicle screws in the lumbar spine. Spine (Phila Pa 1976) 25:615-621, 2000

50. Wiltse LL, Spencer CW: New uses and refinements of the paraspinal approach to the lumbar spine. Spine (Phila Pa 1976) 13:696-706, 1988

51. Young S, Veerapen R, O'Laoire SA: Relief of lumbar canal stenosis using multilevel subarticular fenestrations as an alternative to wide laminectomy: preliminary report. Neurosurgery 23:628-633, 1988

\section{Author Contributions}

Conception and design: Voyadzis, Spitz. Acquisition of data: all authors. Analysis and interpretation of data: Spitz. Drafting the article: Spitz. Critically revising the article: all authors. Reviewed submitted version of manuscript: all authors. Approved the final version of the manuscript on behalf of all authors: Voyadzis. Statistical analysis: Spitz. Administrative/technical/material support: Voyadzis, Sandhu. Study supervision: Voyadzis, Sandhu.

\section{Supplemental Information}

Previous Presentation

Portions of this work were presented in poster form at the 2013 CNS Annual Meeting in San Francisco, CA.

\section{Correspondence}

Jean-Marc Voyadzis, Department of Neurosurgery, Medstar Georgetown University Hospital, 7 PHC, 3800 Reservoir Rd. NW, Washington, DC 20007. email: jmvoyadzis@gmail.com. 